\title{
Conhecendo a colonização da Unidade de Terapia Intensiva do BP Mirante
}

Autores: Silvia Castro Caruso Christ, Flavia Naif Andrieli, Patrícia Dantas da Silva Rebelo, Fernando José da Silva Ramos.

BP - A Beneficência Portuguesa de São Paulo

\section{Introdução}

A colonização por bactérias multirresistentes ocorre em pacientes críticos, em uso de dispositivos invasivos e terapia antimicrobiana de amplo espectro. Devido à suspeita de transmissão cruzada,

identificamos a necessidade de aprimorar e acompanhar os dados do perfil de colonização.

\section{Objetivo}

Descrever o perfil de colonização dos pacientes internados na unidade de terapia intensiva adulto.

\section{Metodologia}

Após análise do evento, foi elaborado um protocolo com critérios para a coleta de swab retal em pacientes internados na UTI/Semi-intensiva. O swab para pesquisa de Bacilo Gram-negativo

multirresistente (BGN) e Enterococo resistente à vancomicina (VRE) é realizado em pacientes com 7 dias ou mais de internação no setor. As coletas ocorrem até a alta, óbito ou positividade do swab.

\section{Principais ações implementadas:}

- Auditorias de processo diária pelo $\mathrm{SCIH}$;

- Treinamento para colaboradores da Higiene e

Limpeza sobre cuidados com o ambiente;

- Implementação de check list para liberação do box após limpeza terminal;

- Implementação do Bundle de Prevenção de Infecção de corrente sanguínea pela unidade;

- Treinamento para colaboradores da enfermagem sobre cuidados durante a preparação e

administração da medicação.

\section{Resultados}

Observamos o predomínio de colonização por Klebsiella produtora de carbapenemase (KPC), Acinetobacter baumanii e Enterococo resistente à Vancomicina (VRE), conforme descrito em literatura. Notificamos apenas uma infecção com o mesmo agente colonizante, não sendo necessário alteração dos protocolos de tratamento empírico das infecções.

Não evidenciamos a ocorrência de infecção por transmissão cruzada envolvendo agentes multirresistentes neste período.
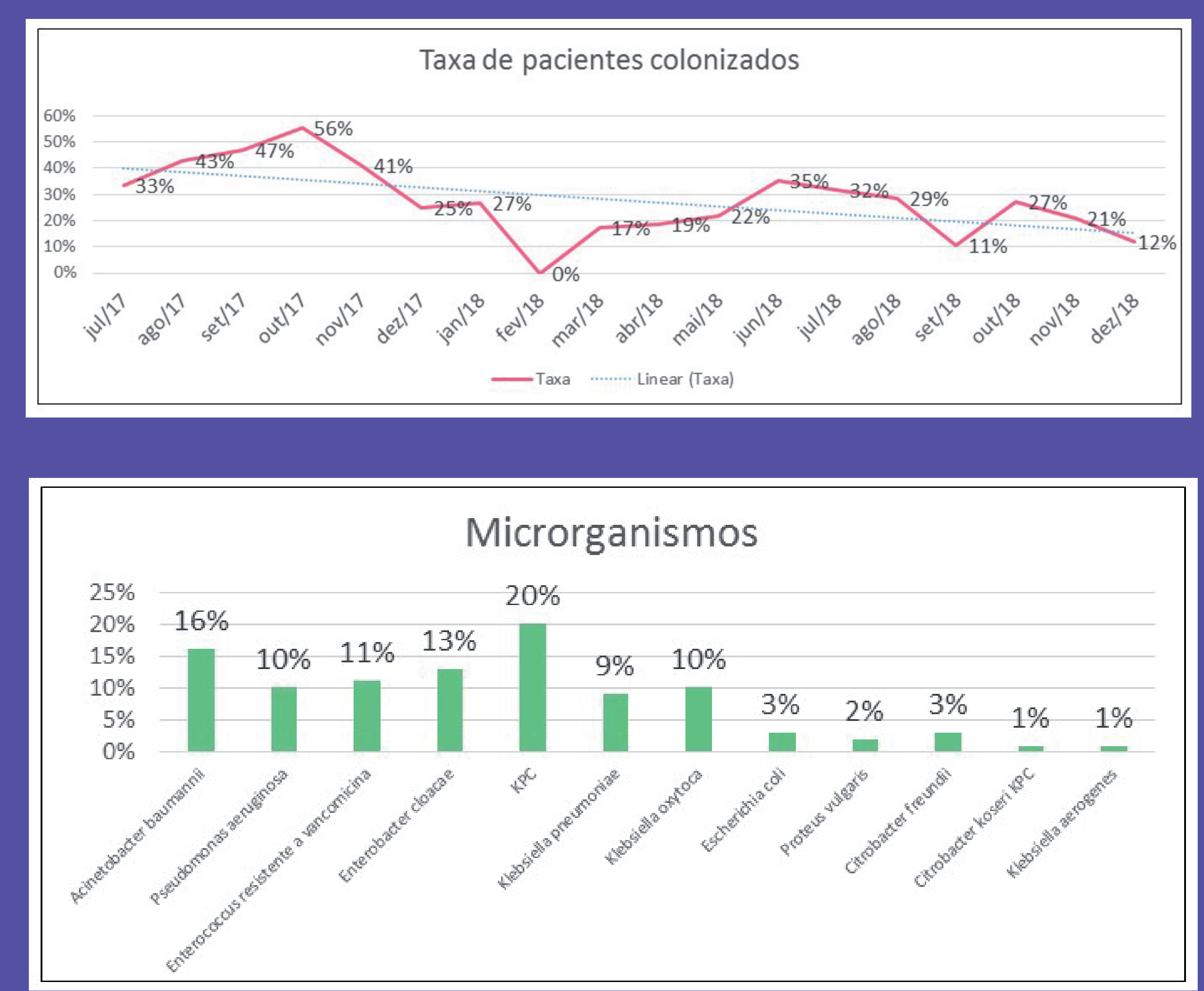

\section{Conclusão}

O monitoramento da taxa de colonização na UTI permitiu a identificação do perfil epidemiológico das bactérias multirresistente contribuindo para a revisão dos protocolos de tratamento e identificação de possível transmissão cruzada. A continuidade do monitoramento permitirá identificar desvios, acompanhamento da eficácia das medidas de prevenção e incidência de agentes colonizantes. O compartilhamento dos dados contribuiu para a sensibilização e engajamento da equipe, ajudando no reforço das ações durante a assistência ao paciente e cuidados com o ambiente. 